\title{
A busca do desenvolvimento através da cultura
}

\author{
João Bugs ${ }^{1}$ \\ Dilani Bassan ${ }^{2}$
}

\section{Resumo}

As desigualdades representam uma das preocupações das gestões públicas, principalmente se forem considerados os bilhões de seres humanos que estão na faixa da pobreza absoluta, portanto passando fome e sem perspectivas de vida. $O$ tema proposto para este artigo teve como objetivo discorrer sobre algumas alternativas diversificadas da cultura brasileira que possam aprofundar o pensamento sobre essas diferenças. Como processo metodológico, foi utilizada a pesquisa bibliográfica, trazendo o olhar de alguns autores sobre o tema. O resultado da análise evidenciou a condição existente de alternativas que possam promover a minimização das desigualdades através do incentivo às potencialidades locais, por meio da disponibilização de recursos, divulgação das regiões e incentivo à reciprocidade como condição de sobrevivência e qualidade de vida.

Palavras-chave: Desigualdades. Diferenças. Cultura. Potencialidades. Desenvolvimento.

\begin{abstract}
Inequalities represent one of the concerns of the public administrations, especially if one considers the billions of human beings that are in the range of absolute poverty, and thus starving and without life prospects. The theme for this paper aims to discuss some alternatives diversified Brazilian culture that may deepen thinking about these differences. As methodological process was used to search bibliographic bringing the look of some authors on the subject. The result of the analysis showed the condition of existing alternatives that may promote the minimization of inequalities by encouraging local potential through the provision of resources, dissemination of regions and encourage reciprocity as a condition of survival and quality of life.
\end{abstract}

Keywords: Inequality. Difference. Culture. Capabilities. Development.

\footnotetext{
${ }^{1}$ Administrador, Contador e Doutorando em Desenvolvimento Regional pela Universidade de Santa Cruz do Sul - UNISC/RS. Professor da UNISC e das Faculdades Integradas de Taquara FACCAT/RS. joaobugs@unisc.br

2 Economista e Doutoranda em Desenvolvimento Regional pela Universidade de Santa Cruz do Sul UNISC/RS. Professora nas Faculdades Integradas de Taquara - FACCAT/RS. dilanib@faccat.br
} 


\section{Introdução}

Frequentemente observa-se, através dos diversos canais de comunicação, a luta de segmentos variados, que, em muitos momentos, torna-se pessoal, para minimizar as desigualdades nos diversos ambientes da vida humana. No entanto, poucos resultados se têm alcançado, tornando-se uma luta desigual na procura de soluções para essas diferenças sociais. Mesmo que as instituições públicas, através dos governos municipais, estaduais e federais, divulguem decisões que visem a minimizar as diferenças, os resultados pouco aparecem.

Verifica-se que o marketing político bem como o corporativo visa, em determinados momentos, à demonstração, aos públicos de seus interesses, de comportamentos de preocupação com os seres humanos e, dentro desta linha, principalmente com os necessitados.

No entanto, na realidade, a prática não condiz com as definições quando se trata de soluções que possam amenizar a pobreza, uma vez que não está sendo efetivamente executada, tornando-se uma ilusória caracterização de responsabilidade, inclusive chegando à condição de haver projetos formatados que mostram a preocupação dos agentes com a causa que são engavetados, evidenciando o descaso com as pessoas em condições de vida de difícil sobrevivência.

Eleva-se, com isso, a necessidade do estudo de meios que atenda às prementes questões sobre a pobreza, razão pela qual o objetivo deste artigo procura trazer alguns caminhos para se pensar sobre as grandes diferenças.

Dentro de uma atitude de esforço, felizmente se presencia cada vez mais um fato relevante e louvável da iniciativa de algumas pessoas em prol dessa luta pela causa, procurando, através de ações pontuais, a geração de alternativas que possam minimizar as diferenças ou mesmo eliminar suas origens, trazendo uma esperança para essas questões que geram cada vez mais angústias e dificuldades de vida de ainda, infelizmente, bilhões de pessoas em nosso planeta Terra.

Espera-se, portanto, que as iniciativas possam criar um pacto de solidariedade e que sejam postas em prática, uma vez que de ideias, geração de alternativas e sugestões, o mundo está cheio. O que está faltando, além de mais iniciativas, é a disponibilidade de recursos, principalmente pelos órgãos públicos 
quando da elaboração de seus orçamentos visando a destinos efetivos de minimização das desigualdades. Também é necessária uma maior iniciativa dos agentes públicos e privados na orientação de caminhos que possam trazer alternativas e participação na geração de renda.

Como a cultura poderá representar, tanto através do saber como através das artes, um dos caminhos para o desenvolvimento? Para responder a essa pergunta, é relevante a análise de algumas possibilidades pela construção de vias que possam disponibilizar às pessoas a procura, por meio da informação e do conhecimento, de uma condição de vida digna e humana.

Para tanto, para aplicar o levantamento e a leitura ao trabalho desejado, a metodologia utilizada foi a pesquisa bibliográfica através de dados e informações trazidas pelas fontes primárias.

\section{$2 \mathrm{Na}$ busca de um desenvolvimento}

Quando se enfatiza que o marketing político e o corporativo, muitas vezes, têm um propósito não direcionado à solução do verdadeiro problema, mas sim na geração de uma imagem do que propriamente de uma ação, parte-se de seu conceito que, segundo Dantas (2010, p. 46), é o seguinte:

[...] um conjunto de atividades que começa com a identificação de
necessidades do público em geral, por meio das pesquisas, continua com o
planejamento, que cuida das estratégias de produto (o político), preço (valor
percebido pelos eleitores em relação ao político e tangibilizado no voto),
promoção e distribuição, segue com a "comercialização" do produto (a
oferta do candidato ao seu público) e termina com a "gerência do produto",
ou seja, a manutenção da imagem do candidato junto ao público durante
todo o período em que durar seu mandato. Durante as fases de
comercialização e gerência do produto utiliza-se a propaganda política.

Percebe-se que a estratégia é bem dirigida: a manutenção da imagem, porém a ação e os efeitos nem sempre condizem com a realidade.

Além disso, para que o marketing corporativo tenha efeito, o qual é definido por Kotler (2000, p. 30) como "[...] um processo social por meio do qual as pessoas e grupos obtêm aquilo de que necessitam e o que desejam com a criação, oferta e 
livre negociação de produtos e serviços de valor com outros", faz-se necessário ter-se o produto, serviço ou a condição proposta, caso contrário é uma divulgação de ilusão.

Nessa situação dicotômica, na qual o propósito se diferencia da ação, já de início se faz necessário, a título de esclarecimento, na busca de um desenvolvimento, tema deste estudo, esclarecer que existe uma diferença na relação entre desenvolvimento e crescimento.

Pode-se considerar desenvolvimento quando houver uma condição de domínio de tecnologias ou mesmo um avanço tecnológico das indústrias, bem como de políticas públicas e privadas que propiciem melhoras no bem estar de sua população. Essa condição pode ser avaliada através de indicadores de pobreza, renda, saúde e educação, como o IDH - Índice de Desenvolvimento Humano por exemplo, utilizado para comparar o desenvolvimento entre diferentes economias. Nesse enfoque, Holanda (1983, p. 28) considera desenvolvimento "[...] como um processo de mudança social global, com implicações não apenas econômicas, como também políticas, sociológicas e culturais".

Já o crescimento tem um viés quantitativo, analisado pelo PIB - Produto Interno Bruto, calculado através da soma de toda a produção e dos serviços prestados no país em um determinado período, comparando o percentual com os períodos anteriores. Portanto, segundo Pereira (1981), entende-se por crescimento econômico aquele crescimento contínuo do produto nacional em termos globais ao longo do tempo, enquanto desenvolvimento econômico representa não só o crescimento da produção nacional, mas também a forma de distribuição social e setorial.

Como a dimensão da pesquisa trata sobre o desenvolvimento que, segundo Sen (2000, p. 10), “[...] consiste na eliminação das privações de liberdade que limitam as escolhas e as oportunidades das pessoas de exercer ponderadamente sua condição de agente", é importante analisar que, para se eliminarem privações ou mesmo trabalhar a questão das desigualdades, é fundamental que se tenha, além da iniciativa e da persistência para tal processo humano e solidário, a liberdade de expressar e desenvolver soluções efetivas para a resolução das causas. Portanto, conforme Sen (2000, p. 52)

[...] as liberdades substantivas incluem capacidades elementares como, por exemplo, ter condições de evitar privações como a fome, a subnutrição, a 
morbidez evitável e a morte prematura, bem como as liberdades associadas a saber ler e fazer cálculos aritméticos, ter participação política e liberdade de expressão.

Pensando dessa forma, é muito importante que as iniciativas e disposições, nesse contexto, sejam desenvolvidas com o enfoque bem definido, uma vez que, ao mesmo tempo que o olhar dos atores veja as dificuldades e distorções da realidade, essa condição não obscureça em sua percepção as possibilidades de reversão de determinados quadros através das oportunidades que muitas vezes se apresentam. Também é necessário que possam ter uma representatividade para uma solução que atenda às necessidades de sobrevivência ou de condição de vida mais digna.

Com isso, a busca de um desenvolvimento visa não somente à divulgação da percepção das desigualdades, da conscientização, da falta de iniciativa e do levantamento de situações que possam minimizar ou resolver a questão das diferenças, ou mesmo a escolha de alternativas e a organização do processo. É mister, principalmente, configurar caminhos que possam servir de motivação para estudos mais aprofundados no sentido de possibilitar a análise do desenvolvimento não somente como estatística, mas principalmente como atitude.

Portanto, Alexander (1965, p. 15) nos remete a uma realidade que dimensiona a nossa preocupação, quando diz que "[...] o mundo de hoje está dividido em países ricos e pobres". Conforme Frost (1965, p. 12), "das 102 nações independentes em que se divide o mundo moderno, 67 são pobres. Representam dois terços da população do globo, mas no que se refere à produção e ao comércio mundial, representam uma pequena minoria". Essa concepção está datada de 1965 e hoje estamos em 2013. Passaram-se quase cinquenta anos, e o quadro permanece praticamente o mesmo, com raras exceções.

Faz-se necessário, porém, atentar para um detalhe esclarecedor: pode haver um país rico e/ou desenvolvido, como por exemplo, a China, que, em 2010, ultrapassou o Japão, tornando-se a segunda maior economia do mundo, mas com uma população pobre, em que mais de 150 milhões de pessoas vivem com menos de US\$1,00 ao dia, ou seja, depois da Índia, a maior população de pobres do mundo, típica de um país subdesenvolvido (2013). 
Um país subdesenvolvido é o resultado de um atraso econômico e social, bem como é produto da dependência externa e da dominação pela elite agrária. $O$ conceito de subdesenvolvimento perpassa a ideia de que a periferia (países pobres) é dependente e dominada pelo centro (países ricos).

Furtado (apud TAVARES, 2000) definiu subdesenvolvimento como uma etapa necessária pela qual teriam passado todos os países desenvolvidos, mas como um processo histórico particular, resultante da penetração das empresas capitalistas modernas em estruturas arcaicas, constitutivo da expansão desigual do capitalismo.

Fazendo uma revisão no conceito de subdesenvolvimento, Florestan Fernandes (apud OLIVEIRA, 2001) considerou que é uma forma de desenvolvimento desigual do capitalismo presente na sua periferia se produz, sobretudo, por uma modernização conservadora, comandada pelas antigas classes dominantes agrárias.

Mas quem são os países ricos e pobres? Neste momento, isso pouco importa: a questão não é analisar os prós e contras de ser rico ou pobre, desenvolvido ou subdesenvolvido, porém buscar compreender alternativas ou formas para reduzir as diferenças. Dentro desse quadro, vislumbra-se, nos dias atuais, com o desenvolvimento cultural buscando passagem, principalmente através das indústrias culturais que utilizam com muita propriedade o crescimento tecnológico, na qual a comunicação exerce um papel relevante, uma condição que deve ser apropriadamente analisada e trabalhada.

Somente por volta de 1980 a palavra cultura foi-se infiltrando inicialmente como cultura organizacional e, com isto, conforme Hermet (2002, p. 85-86) "[...] a cultura saía de um longo ostracismo, pois durante décadas havia sido considerada mais como um fator capaz de paralisar a mudança do que como um possível ponto de apoio do desenvolvimento". No entanto, nos dias atuais, a situação se enquadra em uma outra realidade.

A cultura tem trazido, por intermédio das diversidades locais e regionais, oportunidades para a divulgação das artes individuais e coletivas, tendo como diferencial básico as condições peculiares, incentivando o desenvolvimento por meio da criatividade. 
Segundo Cuéllar (1997, p. 306), "O desenvolvimento terá de ser cultural no século XXI, ou não será". A posição do autor, que, em princípio remete a apenas uma alternativa, traz, integrado a essa afirmativa, o problema da sustentabilidade, em que a cultura é o cerne da questão e representa uma batalha que dimensiona a abrangência sobre o tema.

Portanto, falar em cultura nos dirige a um campo diversificado, dinâmico e muitas vezes na sua dimensão espacial, regionalizado e localizado, trazido pelas raízes do passado cultuadas pela tradição e costumes das famílias. De acordo com Laraia (2001, p. 41),

O homem é o resultado do meio cultural em que foi socializado. Ele é herdeiro de um longo processo acumulativo, que reflete o conhecimento e a experiência adquiridos pelas numerosas gerações que 0 antecederam. A manipulação adequada e criativa desse patrimônio cultural permite as inovações e as invenções.

Mesmo que se tenha a dimensão em um espaço local, a mídia, através das tecnologias de ponta de crescente inovação, possibilita a divulgação de eventos para locais distantes e, às vezes, não percebidos. Essa divulgação traz uma constatação de extrema relevância de que os países pobres ou subdesenvolvidos, mesmo de forma precária, têm acesso à mídia de massa, a qual. através dos seus produtos, propaga condições de vida dignas que o ser humano têm ou teria direito, produtos e novidades que atenda aos grupos de seus patrocinadores.

Logo, o saber da existência e a impossibilidade de ter, convivendo com a sua realidade, não é mais somente frustrante como revoltante. Mesmo que, segundo Alexandre (1965, p. 26-27), "[...] os povos das nações subdesenvolvidas têm sido felizes apesar da pobreza, imundícia e doença, e que se sentem melhor assim como são", ocorre que houve, a partir de então, um novo pensar consciente, quando diz ( $p$. 27): "[...] todavia, o fato importante é que os povos das nações subdesenvolvidas não mais desejam permanecer como estão". No entanto, os pobres, que muitas vezes não têm nem o que comer, teriam oportunidades e forças para reagir?

Essa é uma realidade que se apresenta e que poderá representar uma oportunidade para o Estado, como gestor público, às empresas privadas como organizações impulsionadoras do desenvolvimento, bem como às instituições de ensino e à sociedade civil, representada pela classe privilegiada, a desempenhar um 
papel fundamental de criar alternativas para minimizar os sofrimentos e as diferenças. Resta saber se os gestores públicos, que têm à sua disposição a máquina governamental e podem ser os propulsores da ação, querem realmente trabalhar essas desigualdades de uma forma mais objetiva, desenvolvendo 0 cidadão, integrando-o à comunidade, entenda-se local e, com isso, oportunizar o fortalecimento dos laços comunitários e regionais.

Partindo desse enfoque, dentro das ideias de desenvolver o cidadão, segundo o Sociólogo e Ministro de Estado da Cultura Juca Ferreira (2010), a cultura humana resulta da ação humana e de suas interferências sobre o mundo, tornando visível o pensamento do homem sobre si mesmo e sobre o seu ambiente.

Portanto, um dos caminhos, mesmo que se apresente de uma forma lenta na sua conscientização em nível de Estado, é o segmento cultural, Furtado (1984, p. 25) descreve que "todos os povos lutam para ter acesso ao patrimônio cultural comum da humanidade, o qual se enriquece permanentemente". Essa linha de pensamento caracteriza uma alternativa estratégica viável de ação, na qual a cultura e a indústria cultural poderá representar um diferencial na minimização das desigualdades sociais.

\section{$3 \mathrm{Na}$ busca de um desenvolvimento através da cultura}

Se, há alguns anos, as Nações Unidas adotaram, em seus Relatórios sobre o Desenvolvimento Humano, a ênfase sobre o acesso pleno à cultura como importante indicador para avaliar a qualidade de vida e a considerar estratégicos os processos criativos e simbólicos para o desenvolvimento de uma sociedade, cabe aos agentes públicos incentivar, através de políticas e de investimentos, a realização desse conjunto de práticas e ações sociais. Segundo Furtado (1984, p. 51),

[...] o problema institucional maior que se coloca à sociedade brasileira, no momento presente, é exatamente esse de abrir espaço para emergência e vitalização das forças que alimentam a capacidade criativa da sociedade em todos os planos, forças que entre nós têm profundas raízes regionais.

Dentro desse enfoque, deve-se considerar que a luta contra a pobreza não é somente uma questão técnica, mas política, e que qualquer iniciativa no esforço 
dessa causa deve rigorosamente considerar as desigualdades regionais, ou seja, as diversificadas potencialidades locais e regionais.

Portanto, sem a pretensão de propor alternativas de difícil implementação, busca-se construir algumas vias que poderão servir de incentivo à geração de alternativas capazes de proporcionar a minimização das desigualdades e promover o desenvolvimento local e regional.

\subsection{Construindo uma primeira via}

Busca-se demonstrar aos seres humanos menos favorecidos a possibilidade de olharem a situação dos seus problemas sob outra ótica, se é que consigam avaliar, que as coisas boas da vida trazidas pela mídia poderá ser dentro de determinadas condições, acessível em futuro nem tão distante e, com isso, mexendo com a autoestima das pessoas.

Para tanto, os programas governamentais de ajuda à sobrevivência, tanto quanto à alimentação como à saúde, em que o conjunto de bolsas disponibilizadas pelo Governo Federal participa desse processo, deveriam vir integradas a um projeto maior, no qual a condição de reciprocidade seria a essência fundamental do processo.

Esse projeto maior seria pactuado em duas etapas. A primeira traria uma alternativa de alfabetização, utilizando metodologias de ensino modernas, porém simples, de fácil compreensão e direcionadas à segunda etapa, para praticar o saber ler, escrever e criar, integrado a tarefas obrigatórias para cada participante, com acompanhamento das fases para correção de desvios.

A etapa seguinte seria apropriadamente desenvolvida para cada particularidade local e posteriormente regional, visando à participação em variadas oficinas, como de criação de especiarias locais (artesanato), plantações para geração de produtos específicos, industrialização da matéria-prima gerada na região, comercialização de matéria-prima e produtos locais para outros centros, enfim, desenvolver técnicas que trouxessem uma condição profissional de trabalho especializado.

Segundo Brittos (2004, p. 107), 
[...] há dois modelos ideais de programas de qualificação e formação profissional. Em primeiro lugar, há os programas de formação profissional que complementam a educação básica facilitando a transição da escola para o trabalho, estes são os programas de treinamento de aprendizagem. Em segundo lugar, há os programas de formação profissional voltados para os segmentos de desfavorecidos, principalmente os excluídos e os beneficiários dos programas de 'welfare'; estes são os programas de treinamento para os desfavorecidos.

Sabe-se de antemão que esse processo seria para muitos uma condição de superação. No entanto, pensa-se que o ser humano somente terá um incentivo para atingir uma vida melhor se estiver motivado para viver.

Dentro desse enfoque, a sobrevivência é a base, porém não se pode tirar o direito do ser humano à dignidade. A simples doação, sem a necessidade de nenhum retorno, abafa a condição de grandeza, estabelece uma dependência contínua, além de ser caracterizada pelas outras classes sociais como incentivo ao ócio.

Dessa forma, o Estado estaria exercendo suas políticas públicas através do incentivo e ajuda dentro de uma condição democrática, considerando tanto a ajuda, a solidariedade, como a possibilidade de participação e desenvolvimento pessoal. Inclusive, de acordo com Baquero (2007, p. 57),

[...] os grandes dilemas nacionais - como o das desigualdades sociais, bem exemplificado no fenômeno da pobreza -, naturalmente denotam o sentido de se manter e fazer em bases democráticas os procedimentos necessários à solução das tragédias brasileiras.

Da mesma forma, o Ministro Gil, em seu discurso de posse, afirmou que a política cultural no Governo Lula passou a ser vista como parte do projeto de construção de uma nação democrática e plural, como a essência de um Brasil para todos (apud FERREIRA, 2010).

Se a política cultural passou a ser parte de um projeto maior de construção da nação, cogita-se que a sua aplicabilidade seja real e efetiva, disponibilizando aos agentes responsáveis pelo processo todos os recursos necessários, razão pela qual essa via seria justificável na sua implementação.

\subsection{Construindo uma segunda via}


A história, de uma maneira geral, tem uma importância para a vida das pessoas e das comunidades, mas a sua intangibilidade dificulta a reprodução da realidade. Portanto, construir uma idéia que possa trazer uma condição econômica mínima para as pessoas sobreviverem e sentirem-se úteis e integradas à sociedade nem sempre tem a sua solução na busca das raízes no passado.

De acordo com Baquero (2007, p. 57), "[...] a pobreza econômica rouba das pessoas a liberdade de saciar a fome, e as pessoas famintas vêem-se afetadas em uma condição básica para participar plenamente da vida de sua comunidade". Para participar de iniciativas de caráter individual ou comunitário, as pessoas necessitam estar de bem consigo, motivadas pela condição de satisfazer suas necessidades básicas.

Portanto, como a origem de propósito é o desenvolvimento, que segundo Hermet (2002, p. 23), "[...] só se torna efetivo e digno desse nome se modificar as hierarquias e os papéis, e o faz apoiando-se suficientemente em uma dinâmica interna capaz de gerar uma mobilização tanto produtiva quanto moral da população em questão".

Com isso, para uma mobilização tanto produtiva como moral da população, um dos caminhos pode ser o desenvolvimento cultural através de eventos específicos de comemoração local e regional, cujo processo traz a oportunidade de participação tanto na organização e estruturação do evento sendo custeados por organismos de interesse, bem como nas alternativas diretas e indiretas de geração de renda através da comercialização de produtos e serviços.

Dentro dessa condição endógena, de aproveitamento da diversidade cultural local e regional, a participação dos agentes públicos municipais, da sociedade civil, do estado eclesiástico, das instituições de ensino e das organizações privadas teria um papel importante para a realização dos eventos. Essa realização possibilita a formação de uma identidade própria de um grupo de pessoas que, através da crença, da memória de datas importantes em nível nacional ou mesmo de serviços praticados por políticos renomados, servem de âncora para a concretização dos eventos.

No entanto, surge uma questão a ser analisada: e se os órgãos públicos não tiverem disposição ou mesmo condições orçamentárias para investirem nesse 
propósito? Entra, então, nesse cenário uma nova condição, segundo a qual um agente da iniciativa privada pode assumir essa causa e liderar o processo desde 0 investimento financeiro até a definição das condições de realização. Isso porque, segundo Hermet (2002, p. 184), "[...] certamente esses agentes do desenvolvimento se propõem a remediar assim as carências do exercício vertical ou hierárquico da autoridade política legítima".

Nesse caso, ainda segundo o autor (2002, p. 185) "[...] podem favorecer com suas iniciativas tanto um esmiuçamento cada vez menos coerente das práticas de participação vigentes no país, se essas existirem, quanto há introdução de inovações sem maior alcance por não serem reproduzíveis em outros locais". Por outro lado, pode complicar todo o processo em virtude da "[...] governança participativa ameaçar agravar a impotência de um Estado que optam por ignorar".

Em virtude das dificuldades e das questões políticas envolvidas, uma alternativa seria através da indicação por parte dos órgãos públicos, da empresa ou liderança que realizaria o processo e, com isso, demonstrando a iniciativa do órgão público, porém, disponibilizando para terceiros.

Mas o importante é que essa construção de eventos locais e regionais teria um avanço além do formalmente definido, ou seja, trazer para as comunidades de dificuldades de sobrevivência, em condições de vida muitas vezes paupérrimas, uma possibilidade de ser reconhecida e admirada pelo desenvolvimento criativo de seus atores através de produtos e serviços, em que as manifestações tradicionais, a música, a arte, a dança, as celebrações e festas podem fazer a diferença, além da presença econômica de sustentabilidade.

\subsection{Construindo uma terceira via}

Não é novidade que a mídia, principalmente a televisiva, tem um papel muito importante junto à sociedade. Para tanto, o Estado, como agente regulador, deve disponibilizar as concessões com muita responsabilidade. Segundo Brittos (2004, p. 33), 
[...] O Estado intervém na atividade televisiva de duas formas, como empresário e como agente regulamentador. Quando o Estado outorga novas concessões ou permissões de TV, interfere no mercado e aumenta, de alguma forma, a disputa pelos consumidores.

Essa disputa pelos consumidores tem como princípio, muitas vezes, atender a interesses de patrocinadores e da empresa em preservar audiência para cada vez mais aumentar seus valores das quotas. No entanto, se o entendimento da mídia corporativa for além da questão financeira e tiver o sentimento da sua real importância e interferência na vida das pessoas, pode ser um diferencial na luta contra as desigualdades.

$O$ enfoque dessa alternativa tem por objetivo demonstrar que a mídia corporativa, principalmente a televisiva, pode ser um grande canal de ajuda às pessoas em estado de pobreza e dificuldades, através da propagação de incentivos ou mesmo geração de oportunidades na divulgação de programas disponibilizados pelos órgãos públicos que possibilitem a participação das pessoas, bem como a importante integração das culturas locais. Inclusive, segundo Brittos (2004, p. 111), "[...] muitas vezes a programação conclama os desempregados, subempregados e partícipes do mercado informal a fundarem cooperativas, microempresas e nanonegócios".

Portanto, a mídia procura demonstrar que culturas locais, sendo utilizadas através da união de forças, poderão representar uma alternativa viável para minimizar as angústias originárias das dificuldades. Dentro desse enfoque, a apresentação de eventos que possibilitem a divulgação da arte, da música, do artesanato e de outros trabalhos desenvolvidos pelas pessoas locais servem como um excelente incentivo a propagação da cultura regional.

Da mesma forma, a criação de cooperativas regionais poderia trazer uma alternativa de unir esforços em torno de segmentos das diversidades locais, proporcionando apoio aos partícipes tanto no aspecto organizacional como de estratégias para divulgação e comercialização das especialidades. Segundo Pinho (1966, p. 7),

[...] etimologicamente cooperação (do verbo latino 'cooperari,' de 'cum' e 'operari' - operar juntamente com alguém), significa a prestação de auxílio para um fim comum. Do ponto de vista sociológico, cooperação é uma forma de integração social e pode ser entendida como ação conjugada em 
que pessoas se unem, de modo formal ou informal, para alcançar o mesmo objetivo. A cooperação, quando organizada segunda estatutos previamente estabelecidos, dá origem a determinados grupos sociais.

Portanto, as cooperativas são instituições capazes de proporcionar não somente desenvolvimento econômico, mas também, com a possibilidade de participação democrática e independente, bem estar social para seus associados.

\section{Conclusões}

O estudo procurou trazer a tona algumas preocupações que fazem parte da existência do ser humano e que dimensionam as desigualdades existentes em nossos ambientes de vida. Definiram-se, como eixo-mestre, caminhos que podem vir a ser alternativas de minimizar as causas geradoras da situação de pobreza, buscando o incentivo cultural como mecanismo motivador e incentivador de iniciativas, visando à recuperação da dignidade e da inclusão social.

Nesse enfoque, procurou-se definir alternativas de resgate da cultura local através do envolvimento dos atores residentes, além de oportunizar estudos de vivências sobre a cultura em sua diversidade aos diferentes atores envolvidos no processo de sobrevivência local e regional, possibilitando o desenvolvimento de potencialidades individuais e coletivas que possam ser determinantes e importantes à sociedade.

A questão é, portanto, incentivar a criatividade e o desenvolvimento de alternativas que possam proporcionar retornos para a sobrevivência e melhor qualidade de vida.

Além disso, é necessária a procura do desenvolvimento através das potencialidades locais, incentivando as pessoas de cada ambiente a trabalharem as especialidades, gerando os recursos para a sua sobrevivência e divulgando as regiões. Assim, propõe-se o incentivo à reciprocidade, procurando trazer uma condição de dignidade ao ser humano rejeitado. Enfim, sintetizam-se, de forma simples, algumas alternativas que têm a intenção de promover o pensar das pessoas com referência ao seu conteúdo e, principalmente, servir de base para estudos mais aprofundados sobre o tema. 


\section{Referências}

ALEXANDER, Robert J. O ABC do desenvolvimento econômico. Rio de Janeiro: Fundo de Cultura, 1965.

BAQUERO, Marcelo (Org.). Capital Social, desenvolvimento sustentável e democracia na América Latina. Porto Alegre: UFRGS, 2007.

BRAGA, William Dias. Mediação do trabalho e estratégias de comunicação: flexibilidade e reestruturação produtiva no Brasil. In: JAMBEIRO, Othon; BOLAÑO, César; BRITTOS, Valério (Orgs.). Comunicação, informação e cultura: dinâmicas globais e estruturas de poder. Salvador: Edufba, 2004.

BRITTOS, Valério Cruz. Televisão e barreira: as dimensões estética e regulamentar. In: JAMBEIRO, Othon; BOLAÑO, César; BRITTOS, Valério (Orgs.). Comunicação, informação e cultura: dinâmicas globais e estruturas de poder. Salvador: Edufba, 2004.

CUÉLLAR, Javier P. de (Org.). Nossa diversidade rural. (FAO, 1997). Recife: [s. n.], 1979.

DANTAS, E. B. Marketing Político: técnicas e gestão no contexto brasileiro. São Paulo: Atlas, 2010.

FERREIRA, J. A centralidade da cultura no desenvolvimento. In: BARROSO, Aloísio Sérgio; SOUZA, Renildo (Orgs.). Desenvolvimento: idéias para um projeto nacional. São Paulo: Fundação Maurício Grabois, 2010. p. 265-278. Disponível em: <http://www.cultura.gov.br/site/2010/12/13/a-centralidade-da-cultura-nodesenvolvimento/ capturado>. Acesso em: 30 jun. 2012.

FROST, Raymond. Sociedades Subdesenvolvidas. Rio de Janeiro: Fundo de Cultura, 1965.

FURTADO, C. Cultura e desenvolvimento em época de crise. São Paulo: Paz e Terra, 1984.

HERMET, Guy. Cultura e Desenvolvimento. Petrópolis: Vozes, 2002.

HOLANDA, Nilson. Planejamento e Projetos: uma introdução às técnicas de planejamento e elaboração de projetos. 12. ed. Fortaleza: Universidade Federal do Ceará, 1983.

KOTLER, P. Administração de marketing: a edição do novo milênio. 10. ed. São Paulo: Pearson Prentice Hall, 2000.

LARAIA, Roque de Barros. Cultura: um conceito antropológico. 14. ed. Rio de Janeiro: Jorge Zahar, 2001. 
LIMA, João Vicente R. B; CAMPOS, Rosana. Desigualdades sociais e pobreza: buscando novos enquadramentos. In: BAQUERO, Marcello (Org.). Capital social, desenvolvimento sustentável e democracia na América Latina. Rio Grande do Sul: UFRGS, 2007.

OLIVEIRA, F. de. Subdesenvolvimento: fênix ou extinção? In: TAVARES, Maria da Conceição (Org.). Celso Furtado e o Brasil. São Paulo: Fundação Perseu Abramo, 2001.

OLIVEIRA, M. A. Dilemas na gestão da qualidade e da qualidade de vida no trabalho. In: Encontro internacional de gestão de competências em qualidade de vida no trabalho. Anais. São Paulo: FEA/USP, 2002.

PAÍS SUBDESENVOLVIDO. Disponível em: <http://pt.wikipedia.org/wiki/Pa\%C3\%ADs _subdesenvolvido>. Acesso em: 2 mar. 2013.

PEREIRA, Wlademir. Manual de Introdução à Economia. São Paulo: Saraiva, 1981.

PINHO, D. B. A doutrina cooperativa nos regimes capitalista e socialista. 2. ed. São Paulo: Pioneira, 1966.

SEN, Amartya. Desenvolvimento como liberdade. São Paulo: Companhia das Letras, 2000.

TAVARES, M. da C. (Org.). Subdesenvolvimento, dominação e luta de classes. In: . Celso Furtado e o Brasil. São Paulo: Fundação Perseu Abramo, 2001. 